\title{
FBG-Based Sensing for Structural Health Monitoring of Road Infrastructure
}

\author{
Janis Braunfelds $\mathbb{D}^{1}{ }^{1}$ Ugis Senkans, ${ }^{1}$ Peteris Skels, ${ }^{2}$ Rims Janeliukstis, ${ }^{3}$ Toms Salgals, ${ }^{1}$ \\ Dmitrii Redka, ${ }^{1,4}$ Ilya Lyashuk, ${ }^{1}$ Jurgis Porins, ${ }^{1}$ Sandis Spolitis, ${ }^{1}$ Viktors Haritonovs, ${ }^{2}$ \\ and Vjaceslavs Bobrovs ${ }^{1}$ \\ ${ }^{1}$ Institute of Telecommunications, Riga Technical University, Azenes st. 12, LV-1048 Riga, Latvia \\ ${ }^{2}$ Department of Roads and Bridges Riga Technical University, Kipsalas st. 6B, LV-1048 Riga, Latvia \\ ${ }^{3}$ Institute of Materials and Structures, Riga Technical University, Kipsalas st. 6B, LV-1048 Riga, Latvia \\ ${ }^{4}$ Saint-Petersburg Electrotechnical University "LETI” (ETU), 5 Prof. Popova Street, Saint Petersburg 197376, Russia
}

Correspondence should be addressed to Janis Braunfelds; janis.braunfelds@rtu.lv

Received 1 June 2020; Revised 4 December 2020; Accepted 30 December 2020; Published 9 January 2021

Academic Editor: Christos Riziotis

Copyright ( 2021 Janis Braunfelds et al. This is an open access article distributed under the Creative Commons Attribution License, which permits unrestricted use, distribution, and reproduction in any medium, provided the original work is properly cited.

\begin{abstract}
Public road infrastructure is developed all around the world. To save resources, ensure public safety, and provide longer-lasting road infrastructure, structural health monitoring (SHM) applications for roads have to be researched and developed. Asphalt is one of the largest used surface materials for the road building industry. This material also provides relatively easy fiber optical sensor technology installment, which can be effectively used for SHM applications-road infrastructure monitoring as well as for resource optimization when road building or their repairs are planned. This article focuses on the research of the fiber Bragg grating (FBG) optical temperature and strain sensor applications in road SHM, which is part of the greater interdisciplinary research project started at the Riga Technical University in the year 2017. Experimental work described in this article was realized in one of the largest Latvian road sites where the FBG strain and temperature sensors were installed into asphalt pavement, and experiments were carried out in two main scenarios. Firstly, in a controlled environment with a calibrated falling weight deflectometer (FWD) to test the installed FBG sensors. Secondly, by evaluating the real-time traffic impact on the measured strain and temperature, where different types of vehicles passed the asphalt span in which the sensors were embedded. The findings in this research illustrate that by gathering and combining data from calibrated FWD measurements, measurements from embedded FBG optical sensors which were providing the essential information of how the pavement structure could sustain the load and information about the traffic intensity on the specific road section, and the structural life of the pavement can be evaluated and predicted. Thus, it enables the optimal pavement future design for necessary requirements and constraints as well as efficient use, maintenance, and timely repairs of the public roads, directly contributing to the overall safety of our transportation system.
\end{abstract}

\section{Introduction}

Public roads with asphalt surface material are typically considered as a structure that is exposed to the vibration, strain, and temperature impact on a daily basis. The dangers of underdesign of the road pavement lead to the permanent deformation and even collapsing of the road, which is resulted from significantly higher strain than accounted for in the initial design. Essentially, because the damage done to the roads might not be initially easily and visually observed as well as evaluated, it is important to detect the damage in the early stages of its development [1]. The most common failure modes in asphalt pavement include rutting, cracking, and subsidence [2] caused by channelized traffic and pavement overloading [3].

In order to save the resources and provide longer-lasting infrastructure, a structural health monitoring (SHM) paradigm is rapidly being adopted for the maintenance framework of civil infrastructure including but not limited to roads, buildings [1], bridges $[4,5]$, or slopes with landslide 
possibilities [6]. It is achieved by ensuring a real-time observation and collection of an accurate measurement data related to the structural integrity of the monitored structure or component using transducer technologies. Within the SHM framework, it is possible to detect the damage or specific parameters of interest, initially allowing the responsible authority to react before any serious structural damage has propagated [4]. Thus, the urgency for SHM implementation with time has increased and still is nowadays. However, the complexity of pavement materials due to composition uncertainty, temperature sensitivity, viscoelasticity characteristics [2], and level of compaction [7] is an issue hampering the development of effective means for damage detection and monitoring of road structures.

Fiber optical sensors (FOS) are an effective tool adopted by civil, mechanical, and aerospace engineering communities for temperature and strain monitoring in different structures. Offering numerous advantages, such as multiplexing abilities, robustness, easy integration, lightweight, small size, passive nature, resistance to electromagnetic interference (EMI), and corrosion resistance, [8-10] is compared to the conventional electronic sensors. However, there are only few limitations-fragility of the bare sensors, high cost, and efficiency for transduction mechanisms, as well as interrogation systems complexity. These optical sensors can be integrated into public roads for continuous monitoring. Besides, with further research and commercialization, it is expected that at least some of the disadvantages are about to extinct in the near future [8]. A particular attention in the research community has been on fiber Bragg grating (FBG) optical sensors. In FBG technology, a periodic grating has been inscribed into an optical fiber [11]. The period of grating is influenced by strain and temperature of the surroundings enabling sensing of these physical quantities. According to the Fiber to the Home (FTTH) council organization [12], European governments have been improving their digital infrastructure plans in order to concentrate more on fiber and $5 \mathrm{G}$ technologies, leading to wider availability of public funds that are dedicated to enhancing fiber-based networks. This trend will lead to SHM applications to be more integrated within the fiber optical environment, thus using fiber optical sensors to remotely monitor, for instance, public roads and buildings. For example, by using the already deployed fiber optical infrastructure, the FBG sensor interrogation unit can be located $20 \mathrm{~km}$ or even further from the installed passive FBG sensors, while previously deployed optical lines can be used as a transport layer for the carrying of optical sensors' information.

Numerous studies exist on application of FBG sensors in monitoring of the roads. Several studies have been devoted to a design of appropriate encapsulation of bare fibers before integration into pavements as the fibers themselves are fragile and can easily break [13-15]. In [16], authors, firstly, applied a simple layer of an epoxy resin curing and toughening agents and, subsequently, provided a steel casing encapsulation $(E=198 \mathrm{GPa})$ for increased safety, as laying of pavement implies the use of a heavy (about 30 tons) road rollers. In [17], a special fiber-reinforced polymer with linear elasticity, good fatigue resistance, corrosion resistance, and lightweight for encapsulation of FBG sensors was proposed. Authors argued that this kind of packaging ensures large enough measurement range, ease of application, good durability, longterm stability, and resistance to elevated temperatures. In [18], researchers developed a new FBG sensor encapsulation approach based on compliance of elastic modulus of FBG sensor packaging and surrounding asphalt pavement. This implies the use of low-modulus coatings for FBG optical fibers in order to prevent the strain field, as sensed by FBG sensors, from distortion. In [19], commercial solution from Monitor Optics Systems Ltd. was proposed, and it consisted of glass fiber composite optical sensing cable, in which several optical fibers can be embedded. The cable itself can reach several kilometers in length, and it can be tailored to enable a proper transfer of mechanical stresses from a structure to the sensor. It is compatible with epoxy resin adhesives for better surface bonding or embedment of sensors. The cable can also be surface treated for added protection regarding the environmental effects. The system was successfully deployed for highway pavement monitoring in Australia.

The performance of embedded FBG sensors within asphalt pavement was researched in studies [13-15]. Static tests of asphalt concrete specimens, with embedded FBG sensors, showed a linear relationship between wavelength shift and strain of the asphalt concrete thus satisfactory repeatability of the test [16]. The authors also studied the response of the sensors to understand the impact of loading heavy traffic under high speeds by simulating it with a drop hammer. The findings were that the relationship between the frequency of impacts and asphalt concrete strain can be approximated with a cubic function with a coefficient of determination equal to 0.9978 . Two distinct phases were noticed in the growth of strain with increasing frequency of impacts-faster growth of cumulative plastic strain initially and a more stable growth in the later phase. Three FBG sensors were interconnected in a $3 \mathrm{D}$ manner for measuring strains in vertical and two transverse directions simultaneously [17]. This assembly was then embedded into highway pavement for strain monitoring. Researchers in [2] proposed a novel "self-healing" FBG optical sensor technology for pavement monitoring. This technology implies the use of self-repair sensor nodes that are based on the "smart" light switching where the light impulses are necessary for sensor operation and are still transmitted through the path, even if the sensors are damaged. FBG optical sensors can also be used in carrying out quality control of compaction of an asphalt pavement. This study was presented in [7]. For this purpose, the traditional FBG sensor was modified with a load-bearing plate. Fixing part and support legs were used for increased stability. This sensor was then embedded into an asphalt mixture. The differences between strain, as measured by this sensor, indicate the areas where asphalt is under compaction or over compaction. In [20], the FBG sensor network was employed to measure the hydrodynamic pressure of an asphalt pavement surface at different vehicle speeds. It was found that the correlation coefficient between the wavelength shift of the sensors and the pressure is 0.99 , suggesting a solid application of an FBG sensor technology in the evaluation of hydrodynamic pressure at the surface of asphalt pavement. The 


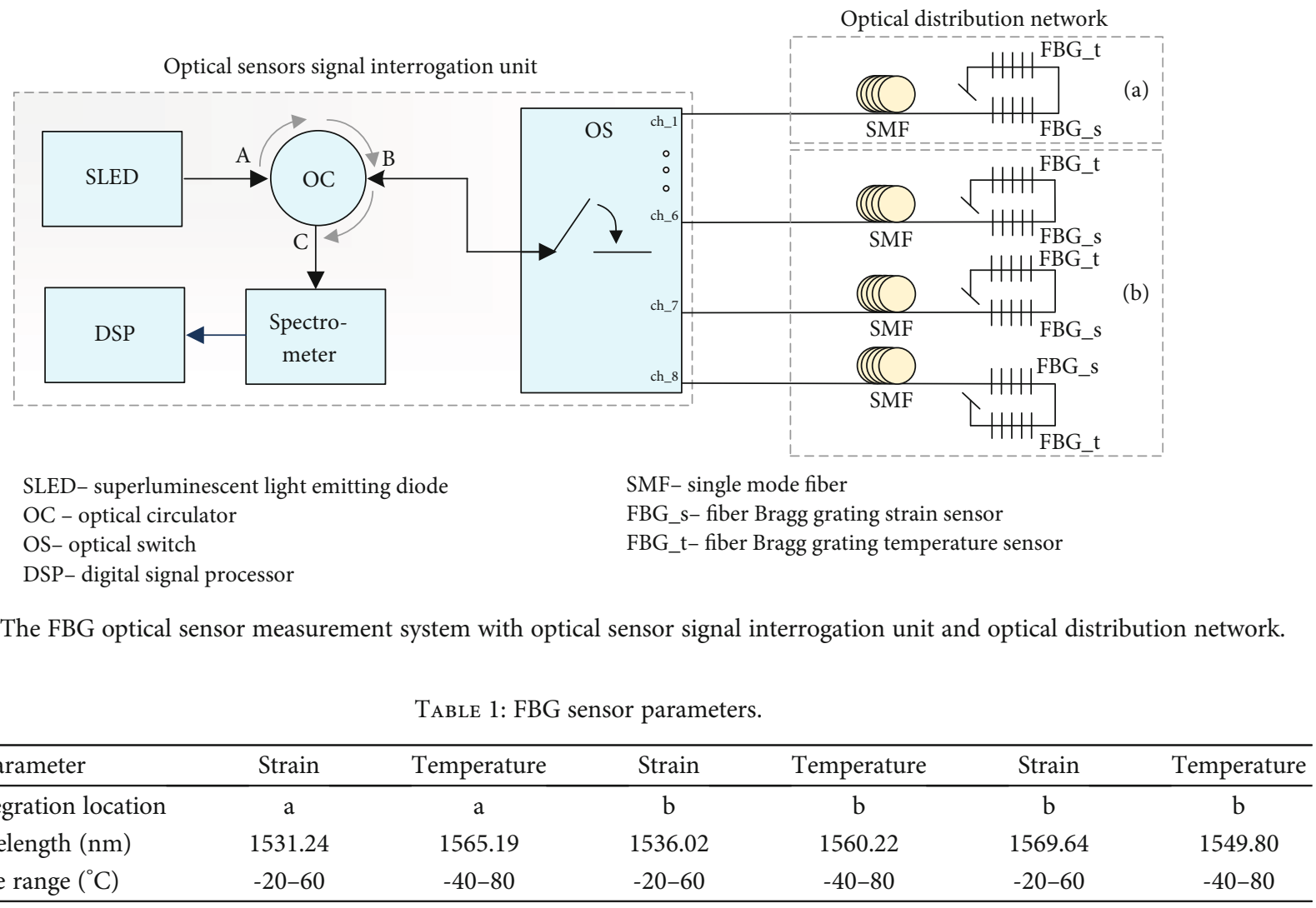

accumulated deformations in various layers of the asphalt (with FBG sensor network) at different temperatures were monitored in [3]. It was found that the accumulated deformation has a tendency to propagate from middle layers to deeper layers with increasing temperature, and also that, in general, the accumulated deformation increases with temperature for top and bottom layers, but not for the middle layers. This phenomenon was also observed and approved during this research, when strain parameters were measured in different seasons (shown in Section 3.1.). In [13], authors employed a novel FBG sensor laying technique for laying asphalt pavements. This implied a cross-sectional laying so that FBG sensors would simultaneously be capable of measuring strain in longitudinal and transverse directions. FBG sensors are known to have a drawback of not being able to effectively distinguish between strain and temperature field measurements if used as a single sensor. The potential solution to this problem is proposed in [21], where a reference grating sensor (for temperature measurements only) is combined with a dual-wavelength grating sensor, in which two FBG sensors are superimposed in order to discern between temperature and strain responses. Adding to that, research [22] shows that based on the FBG's strain and temperature sensing principles, dual FBG temperature compensation is important. While using two different fiber Bragg gratings that are inscribed into one optical fiber (where one is affected by strain and temperature, while the other one is strain isolated), it is possible to gather more accurate data, thus ensuring the possible solutions that can be appealing for a longterm structural monitoring system application. This method, for distinguishing between strain and temperature, was also used in this research experiments. It can be further concluded that it is of paramount importance to develop reliable and effective mechanical strain monitoring technologies for asphalt pavement structures in order to, firstly, provide the means for early warning of deterioration of road quality and secondary-contribute to an accurate scientific basis to modify the existing scientific theories of asphalt mechanics.

In the current study, the FBG FOS was used for interconnected experimental scenarios as described in this paper. The first scenario deals with a falling weight deflectometer (FWD) to numerically and visually evaluate the response of the optical sensors that were integrated within the road that is being built. The second experimental scenario describes the integration of FBGs within the surface of the public road asphalt, where real-time traffic was observed, especially focusing on the heavy trucks that induce the highest strain in the pavement.

Further sections are organized as follows. Section 2 describes the experimental setup and scenarios with the falling weight deflectometer and real-time traffic monitoring. Results are presented in Section 3. Finally, conclusions are made, showing the methodology and future research directions.

\section{Experimental Methods}

The experiments described in the following subsections are very topical for Northern and Eastern Europe including Latvian road pavement designers in order to forecast the 


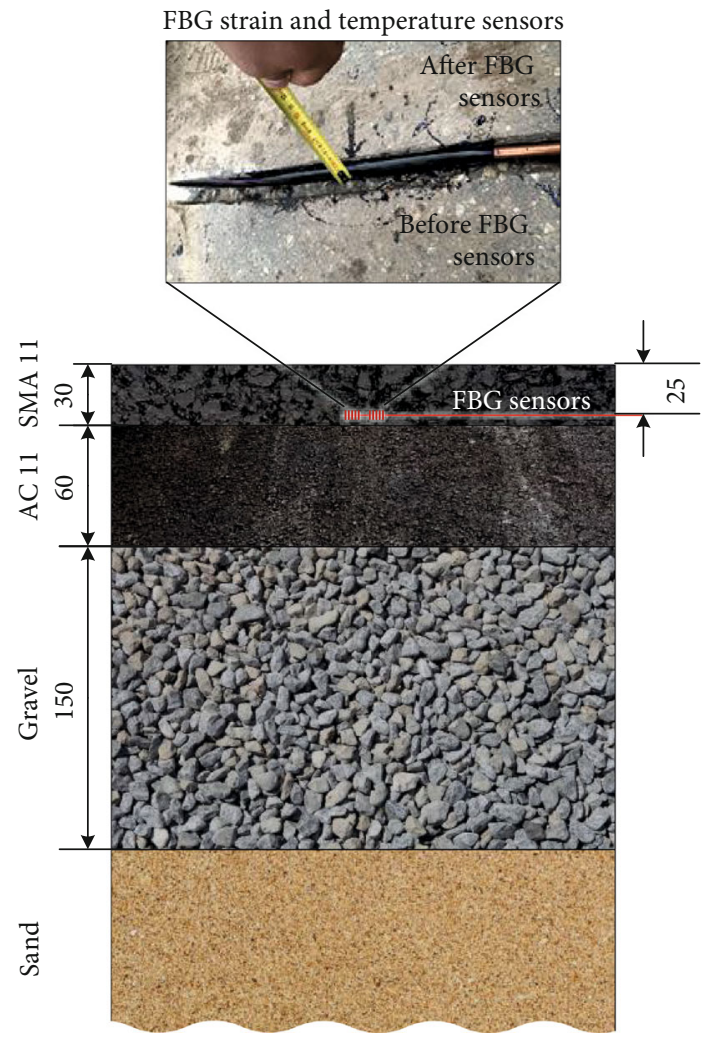

FIgURE 2: The structure of road layers in location (a).

structural integrity of the designed roads. Two different but interconnected experimental measurement scenarios involve using falling weight deflectometer (FWD) (for assessment of the FBG sensor operation) and measurements of the realtime strain traffic.

Both of the scenarios were realized as a field measurement by using the setup shown in Figure 1.

For our experimental research, it was necessary to plan the overall scheme of components and networks. Here, for both measurement scenarios, we used specially developed multichannel optical sensor signal interrogation unit that was used for processing of our acquired data regarding fiber optical sensor information during our research phases. Remote operation distance for optical sensor signal interrogation is more than $40 \mathrm{~km}$. This unit was connected with the optical distribution network (ODN) where our FBG temperature and strain optical sensors were positioned.

Figure 1 shows the experimental measurement setup used for tests with FWD and monitoring of real-time traffic, having two main parts-optical sensor signal interrogation unit (OSSIU) and ODN with embedded FBG optical sensor network. High power superluminescent emitting diode (SLED) source with a central wavelength of $1550 \mathrm{~nm}$ and 3$\mathrm{dB}$ bandwidth of $55 \mathrm{~nm}$ fully covering the optical C band $(1530 \mathrm{~nm}$ to $1565 \mathrm{~nm})$ is used in the OSSIU unit as a broadband light source. This unit also has optical time-domain reflectometer (OTDR) capability, which is in parallel to FBG sensor interrogation that was used for monitoring of the ODN, to avoid possible damage, faults, or excessive macrobending of the optical fibers attached to these optical

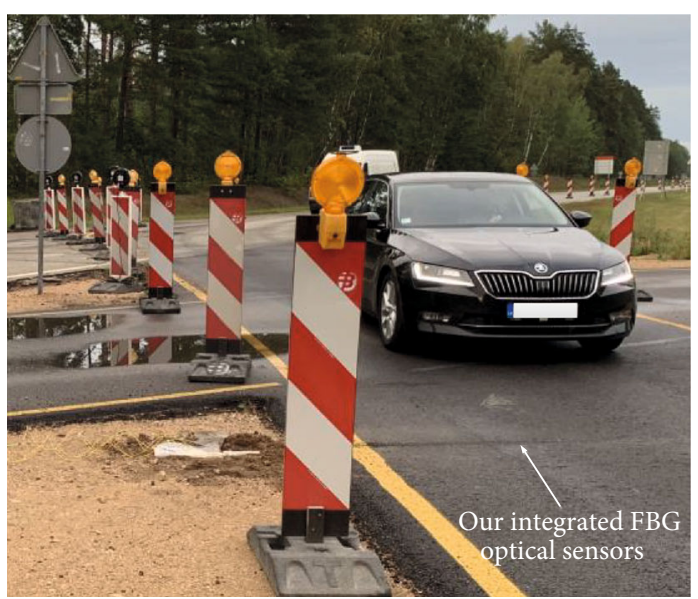

FIGURE 3: Embedded FBG sensors on the carriageway in the location (b).

sensors. In Figure 1, the optical sensor signal interrogation unit is not shown, as it is not the focus of this article.

The output of SLED is connected to the optical circulator's (OC) port number 3 for separation of the optical signal flows. SLED's signal is transmitted from port A to port B, while FBG sensors reflected signal-from port B to port C. Afterward, port $\mathrm{B}$ of the $\mathrm{OC}$ is connected to the input of the optical switch (OS). The optical switch has 8 fiber channels, and it was used to connect each channel at a specific time interval. Four channels of the optical switch were used for the connection of the ODN sensor network, but the rest of the channels were not necessary for the described experiments. Each of the ODN sensor network channels consist of the ITU-T G.652 single-mode optical fiber (SMF), FBG strain, and temperature sensors. In the ODN (location a), part (OS fiber port 1) represents the connection for first measurement scenario-the setup for measurements with falling weight deflectometer (FWD), but (location b) represents second measurement scenario (OS fiber ports 6 to 8 ) -real-time applied traffic strain measurements of the road with integrated FBG optical sensors (FBG sensors parameters shown in Table 1.), as it is further discussed in Section 3.2.

Additional FBG temperature sensors were used to compensate temperature changes in strain measurements. FBG sensor reflected signal is transmitted from $\mathrm{OC}$, port $\mathrm{C}$, to the spectrometer with a $10 \mathrm{kHz}$ maximal scan frequency for 1 optical channel. The digital signal processor receives spectrometer data, detects sensor signal central frequency, and mathematically calculates temperature and strain values. The results of the measurements are then plotted against time.

2.1. Embedding FBG Sensors for Strain Monitoring. The location for FBG optical sensor integration into the real pavement structure was chosen in accordance with the recommendation given in European Weigh-In-Motion (WIM) specifications COST-323 [23]. This document states that the site of sensor embedment should satisfy the following requirements: 


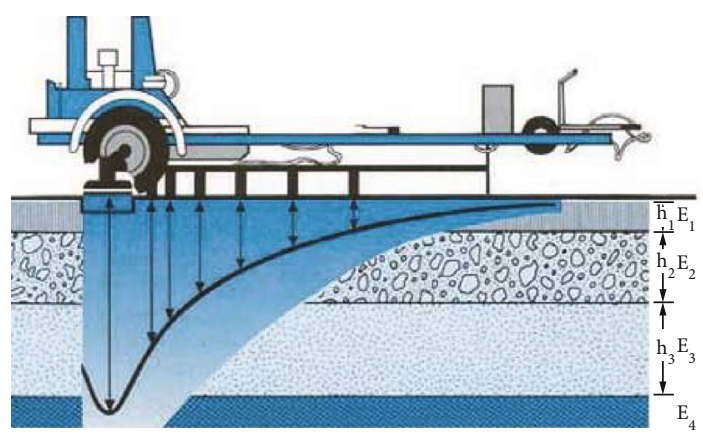

(a) The operation principle [27]

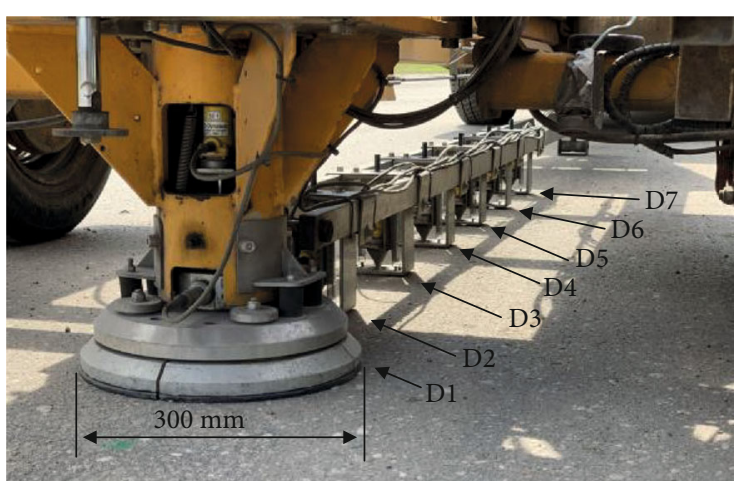

(b) D1-D7 deflection sensors

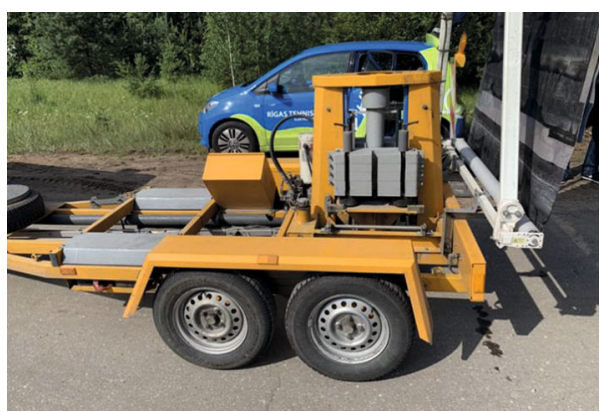

(c) Dynatest 8000 FWD model used in this study

FIGURE 4: FWD equipment for testing the pavement structure.

(i) Longitudinal slope $<1 \%$

(ii) Transverse slope $<1 \%$

(iii) Radius of curvature $>2500 \mathrm{~m}$

(iv) The surface shall be smooth and maintained in a condition that complies with the International Roughness Index $(\mathrm{m} / \mathrm{km})-0-4$

For embedding of the FBG sensors and measurements, it was found that the pavement structure in Latvia is going to be built in the construction season of 2019-2020. With the help of the contracting company "Binders" Ltd., which is performing the pavement reconstruction projects of the main road, the A2 Riga-Sigulda-Estonian border km 25.50-39.40 (both carriageways) was chosen for embedding the FBG strain and temperature sensors in 2 locations. This road section connects Riga (the capital of Latvia) with the Estonian border.

According to the location (a), commercial FBG sensors were implemented between SMA11 (stone mastic asphalt) (30 mm thick layer from the top coat) and AC11 (asphalt concrete) (60 mm thick layer) asphalt layers. To provide the protection of the FBG sensors and correct operation, strain sensors are integrated into glass/epoxy composite patches $(250 \times 15 \mathrm{~mm})$, but temperature sensors in ceramic tube. FBG's temperature sensor ceramic tube (diameter: $3 \mathrm{~mm}$, length: $23 \mathrm{~mm}$ ) isolated strain changes. Length of the FBG strain sensor's grating, according to the specification provided by the manufacturer, was $10 \mathrm{~mm}$. In our solution, we used this FBG sensor thus-optical fiber, and positioned it between 2 glass/epoxy composite material plates.

The operation temperature range of temperature sensors is $-40-80^{\circ} \mathrm{C}$, but strain sensors $-20-60^{\circ} \mathrm{C}$. The graphical representation of these layers is shown in Figure 2. The FBG strain and temperature sensors were fixed on the crosssection of the asphalt at the $25 \mathrm{~mm}$ depth. In this location, FWD equipment is used for testing of the sensor's integration quality and pavement structure. Tests with FWD equipment were realized in seven different scenarios (when FWD was located to the sensors within range of 300,600 , or $900 \mathrm{~mm}$ after the FBG strain sensor).

In location (a), FBG sensors are integrated into the road with geographical location point coordinates: $57^{\circ} 07^{\prime} 18.4^{\prime \prime} \mathrm{N}$ $24^{\circ} 40^{\prime} 02.6^{\prime \prime} \mathrm{E}$. The FBG implementation in both locations is realized after the construction of the road.

As for location (b), FBG strain and temperature sensors (the same sensors as in location (a)) were embedded on the border in a $70 \mathrm{~mm}$ thick homogeneous AC 11 one-layer system. Both strain sensors were fixed on the section of asphalt (exactly the same as for location (a)). Long cut was created, and sensors were attached to the cut walls -1 on the one side and 1 on the other one, at the following depth- $25 \mathrm{~mm}$ on both sides (the same depth as in location (a)). The temperature sensors were fixed in the predrilled holes next to the strain sensors. In location (b), the FBG sensors are embedded in the entry to the $\mathrm{A} 2$ temporary road with geographical location point coordinates: $57^{\circ} 07^{\prime} 07.4^{\prime \prime} \mathrm{N} 24^{\circ} 39^{\prime} 04.1^{\prime \prime} \mathrm{E}$ (see Figure 3). 


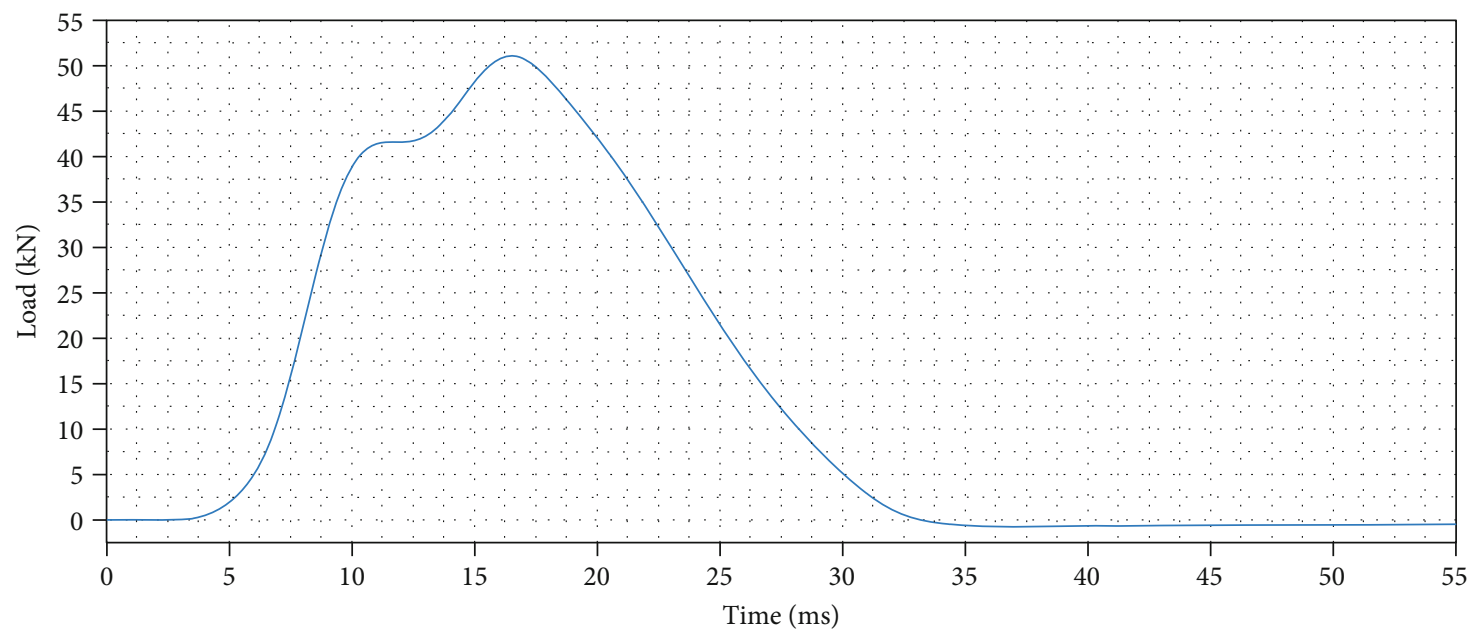

FIGURE 5: Measured FWD pulse load result for the last drop when distance between FWD and embedded FBG strain sensor is 300 mm.

\subsection{Experiments with the Falling Weight Deflectometer and} Embedded FBG Sensors. Falling weight deflectometers (FWDs) are in widespread use for nondestructive pavement testing and used as a research or structural evaluation method [24-26]. FWD data is most often used to calculate stiffnessrelated parameters of the pavement structure. The process of calculating the elastic modulus of individual layers in a multilayer system based on the surface deflections is known as "back-calculation", as there is no closed-form solution [2729]. When using the FWD, surface deflection measurements are necessary for processing back-calculations of specific material properties. Such properties are based on assumptions for the pavement response to a load, thus allowing applying the strain value that is deliberate for the pavement structural and fatigue analysis. Therefore, the precision of the results (strain at the critical location in the pavement structure) is dependent on the assumptions made during the analysis [28].

FWD equipment is typically used to measure the road pavement deflection with its deflection sensors (D1-D7), but in this research, this equipment was used for getting the fixed and calibrated load values that were made from the circular load plate.

In the measurement session, an FWD equipment, optical sensors signal interrogation unit (OSSIU), and FBG strain as well as temperature sensors were embedded in the road pavement 2 laptops-1 for FWD and 1 for OSSIU controlling that were also used. The load is applied by dropping a known weight, and it is transmitted to the road pavement through a circular load plate-300 $\mathrm{mm}$ in diameter (see Figure 4(a)). A load cell is mounted on the top of the load plate, and it measures the load that is imparted to the pavement surface. According to the European practice, the typical load for the road testing is $50 \mathrm{kN}$ giving about $707 \mathrm{kPa}$ pressure under the load plate. Deflection sensors (geophones; force-balance seismometers) are mounted radially from the center of the load plate in order to measure the deformation of the pavement in response to the load [27]. The FWD system is equipped with seven (D1-D7) deflection sensors, and offsets between sensors are from 0 to $1800 \mathrm{~mm}$ with increments of $300 \mathrm{~mm}$ (see Figure 4(b)). The Dynatest 8000 FWD equipment (shown in Figure 4(c)) owned by the

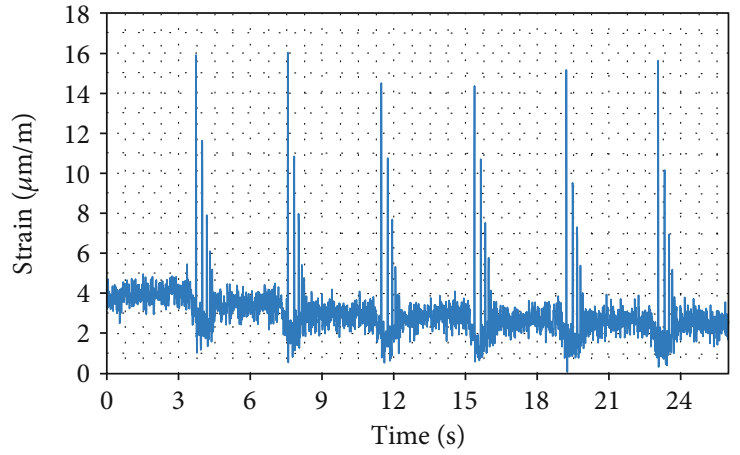

FIgURE 6: Strain versus time measured by the FBG sensor, embedded $25 \mathrm{~mm}$ under FWD and center of the FWD load plate, is located $900 \mathrm{~mm}$ after FBG sensor.

State Joint Stock Company Latvian State Roads was used for testing the pavement structure. The depth profile of the road in location (a) and the embedded FBG sensors (FBG strain sensor and FBG temperature sensor for temperature compensation) were located within the structure in between the pavement structure layers as are shown in Figure 2.

FWD equipment was used in a mode of six weight drops with a fixed $50 \mathrm{kN}$ load at four different scenarios, where in the first scenario, the center of the FWD load plate was located directly on the FBG strain sensor. In other scenarios, distance between the FWD load plate and FBG strain sensor was 300,600 , or $900 \mathrm{~mm}$. It is important to note that the FBG sensor is integrated on the right side of the road pavement layer (see the upper part of Figure 2), corresponding to "FWD $300 \mathrm{~mm}$ after FBG sensor". In FWD software, all drops were set with the same load, which is $50 \mathrm{kN}$. The FWD equipment after the drop measured drops' load with its sensors. It was observed that in full measurement, session the load variated till $1 \%$. This described measurement session was realized in summer 2019, when, during the measurement day the road pavement temperature varied from +18.7 to $+22.5^{\circ} \mathrm{C}$ (temperature measured with FBG sensor). 
TABLE 2: Measured strain $(\mu \mathrm{m} / \mathrm{m})$ by FBG sensor that is embedded $25 \mathrm{~mm}$ under FWD when 6 drops by $48.9 \pm 0.5 \mathrm{kN}$ load are performed (with temperature compensation enabled).

\begin{tabular}{|c|c|c|c|c|}
\hline \multirow{2}{*}{ No. of FWD drop } & \multicolumn{4}{|c|}{ Center location of the FWD plate with respect to the FBG sensor (mm) } \\
\hline & 0 & 300 & 600 & 900 \\
\hline 1 & 162.5 & 91.5 & 24.6 & 12.5 \\
\hline 2 & 145.9 & 77.6 & 27.0 & 13.1 \\
\hline 3 & 142.7 & 80.5 & 24.2 & 12.2 \\
\hline 4 & 149.5 & 73.4 & 28.3 & 12.1 \\
\hline 5 & 161.6 & 85.8 & 25.7 & 13.2 \\
\hline 6 & 148.5 & 71.2 & 25.1 & 13.2 \\
\hline Average value of measured strain $(\mu \mathrm{m} / \mathrm{m})$ & $151.8 \pm 9.9$ & $80.0 \pm 10.2$ & $25.8 \pm 2.1$ & $12.7 \pm 0.6$ \\
\hline
\end{tabular}

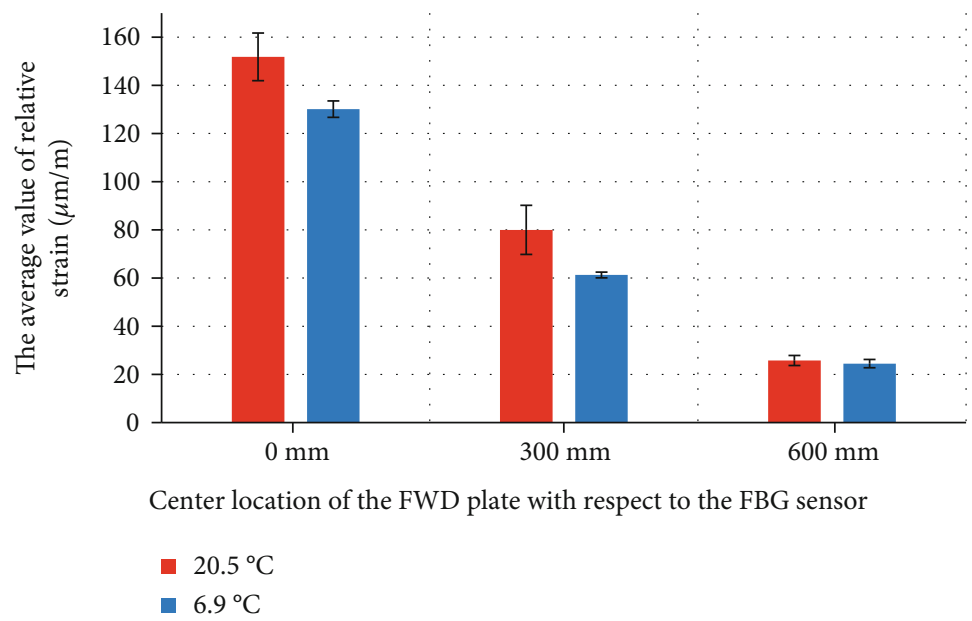

Figure 7: Average value of strain for FWD drops when road temperature is $6.9^{\circ} \mathrm{C}$ and $20.5^{\circ} \mathrm{C}$.

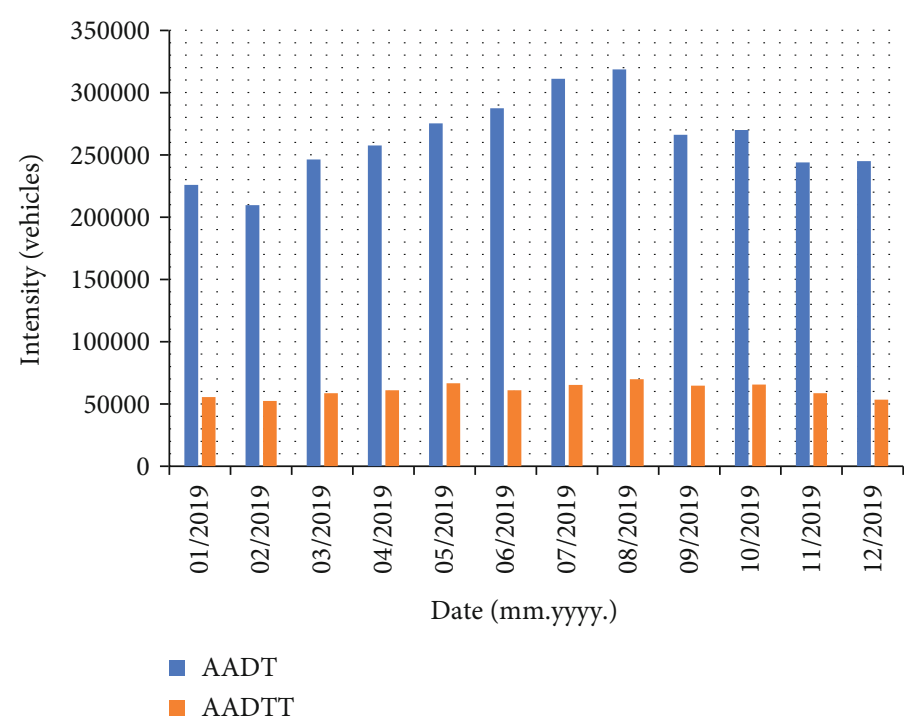

FIgURE 8: Traffic intensity in 2019 at highway A2 $76^{\text {th }} \mathrm{km}[30]$.

\section{Results}

3.1. Strain Measurements from FWD Drops with the FBG Sensors. The load of the falling weight versus time for one drop of circular load plate (pulse) was measured with FWD to analyze equipment's working principle (see Figure 5). The total duration of load pulse initiated by FWD equipment drop is $30.35 \mathrm{~ms}$, and load peak value $51.09 \mathrm{kN}$ is achieved at $16.5 \mathrm{~ms}$. 


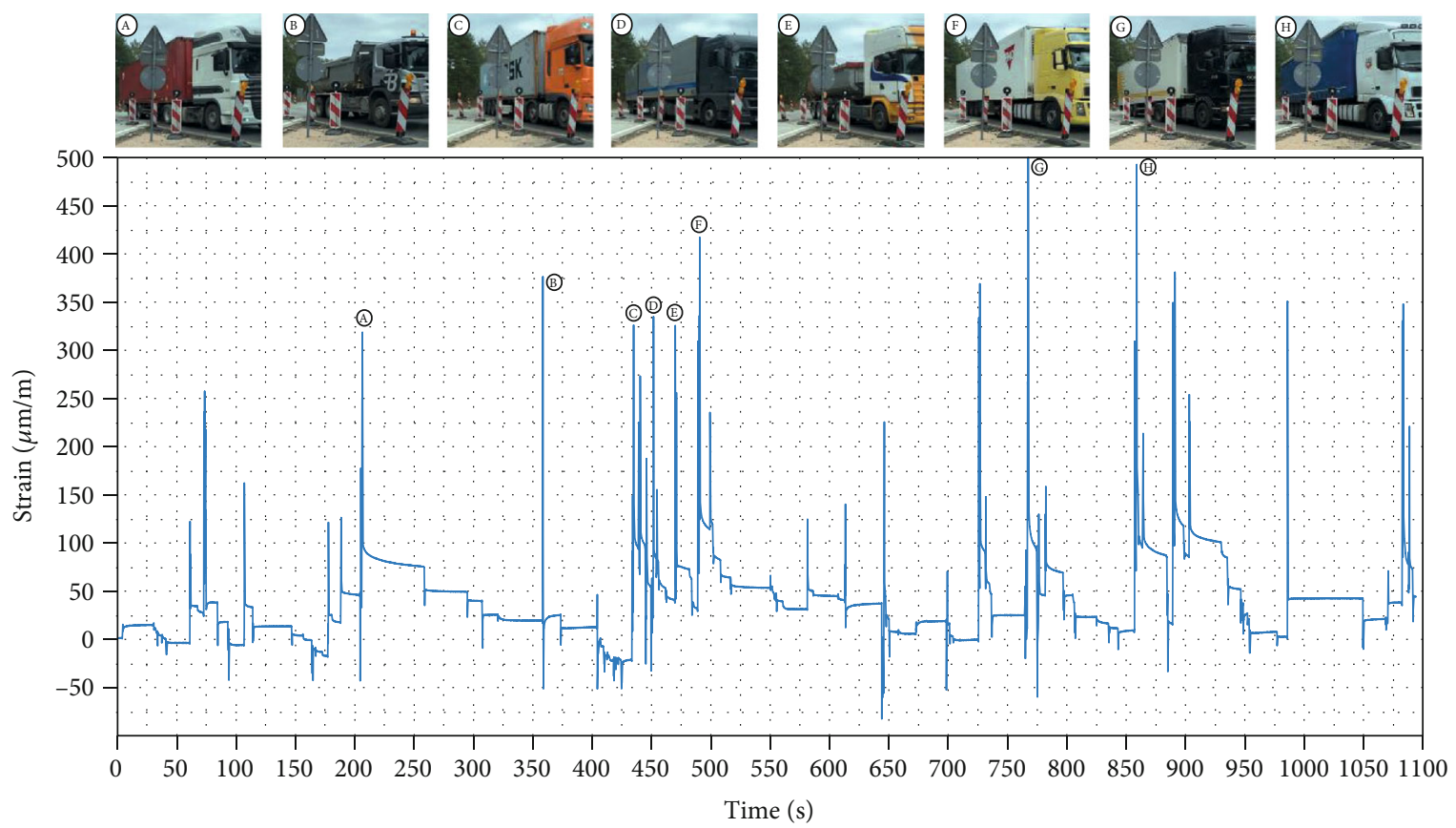

FIGURE 9: Measured real-time strain graph of passing traffic by the embedded FBG sensor.

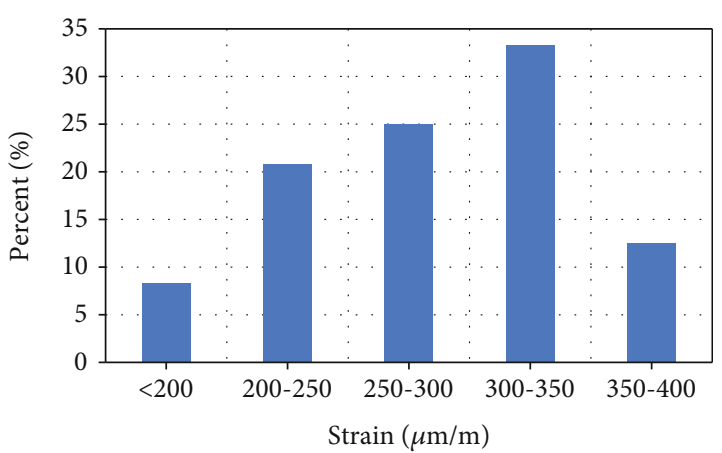

FIGURE 10: Histogram of truck generated strain values measured with embedded FBG sensors.

The strain that was measured with the FBG sensor embedded $25 \mathrm{~mm}$ under the FWD load of 6 drops is illustrated in Figure 6 (in scenario-when the center of the FWD load plate was located $900 \mathrm{~mm}$ after FBG sensor (see Figure 6)).

Six stable peaks can be observed. The relative scatter of $4.7 \%$ (Figure 6) over all six drops of the FWD plate was registered for a mean load of $48.9 \pm 0.5 \mathrm{kN}$. Peaks with smaller strain amplitude can be seen after every major peak. Those represent FWD amortization drops for equipment stabilization and positioning at rest.

In Table 2, measured strain can also be seen. They are also known as a relative deformation values that represent FBG optical sensors after temperature compensation for each drop. These strain values that are showed in Table 2 represent the difference between strain minimum (strain floor) and measured peak maximum.

As it can be seen in Table 2, results gathered with the FBG sensors show the possibility to precisely (the relative scatter
4.8-12.8\%) detect the strain values, which allows to evaluate the real operation of the pavement structure under load.

FBG strain sensors are fixed to the asphalt side, then monitoring with high accuracy can be realized from the side where the sensor is embedded. This is the main disadvantage of this method, which must be taken into account when applying the integration process of the sensors. For fixed one-way traffic, it does not create monitoring restrictions, but if the traffic direction is changing, then it is necessary to integrate FBG sensors on both sides.

In order to evaluate the impact of the road surface temperature on the measured strain, another session of measurements, therefore, was repeated in autumn 2019. The measured average strain values after temperature compensation for each drop are shown in Figure 7 where comparison is made of the strain values between the ones that were gathered during summer versus the other ones-during autumn, when road pavement temperatures measured with FBG sensors were $20.5^{\circ} \mathrm{C}$ and $6.9^{\circ} \mathrm{C}$. In the graph, error bars represent strain relative scatter. The same loading parameters were used in the autumn session ( 6 drops with $50 \mathrm{kN}$ load each) with the mean measured load of drops equal to $51.98 \pm 0.94 \mathrm{kN}$.

These values are equal to the difference between strain minimum (strain floor) and measured peak maximum. As it can be seen, the highest strain value (averaging $151.8 \pm$ $9.9 \mu \mathrm{m} / \mathrm{m}$ ) is detected when the center of the FWD load plate is located over the embedded FBG strain sensor. In the light of these findings, the sensor placement with respect to the direction of passing vehicles plays an important role. As can also be seen, all values of the measured strain were lower in autumn compared to summer. Same tendency was observed in [3] research. The strain values were higher in warmer weather, because of the stiffness that decreases at higher temperatures; so, as a result, strain values are 
increasing. Therefore, it is very important to take into account the temperature of the road when carrying out the second part of our research-strain measurements from passing vehicles.

3.2. Real-Time Traffic Analysis. Monitoring of the real-time vehicle traffic described in this article was realized in September 2019, in the temporary road section-location (b) shown in Figure 3, where FBG optical sensors were used without using FWD equipment. The average temperature for the road pavement (measured with FBG temperature sensor) during the measurements was $+25.2^{\circ} \mathrm{C}$. For embedding of the sensors, we chose the location, where there is a high annual average daily traffic (AADT) and annual average daily truck traffic (AADTT). The data of the nearest traffic counting point (station No. 6) showed that there were 3.15 million vehicle intensity in 2019 with an average speed of $86.4 \mathrm{~km} / \mathrm{h}$. From all the passing vehicles, $23.3 \%$ or 735000 were specifically truck intensity (see Figure 8) [30]. In this location, the sensors were embedded in the temporary road section provided by Binders Ltd., which is the largest Latvian road construction company.

Figure 9 can be seen in a short time period of the measured vehicle traffic strain changes gathered from the FBG sensor no. 2 (fixed on the right side-depth $25 \mathrm{~mm}$, exactly the same as for location (a)). Parallel to the real-time strain measurements, a video was taken in order to be certain that the road traffic changes are calibrated with the strain measurements, as well as to see the "strain-pattern" of different vehicles, mainly trucks. It can be seen that the truck traffic in particular is generating the highest strain in the pavement structure. If the graph is zoomed in, then the number of vehicle axis and the strain value of each vehicle axis can be detected. From the measured FBG strain, sensor data shows that the "G" truck's last axis $\left(5^{\text {th }}\right)$ creates the highest strain or relative deformation value, which is $375.6 \mu \mathrm{m} / \mathrm{m}$. The second highest strain value $(356.4 \mu \mathrm{m} / \mathrm{m})$ was created by the "B" gravel truck that has 3 axes. It is important to note that in Figure 9, upper part visually does not show all of the trucks that were passing by, for example, at the time spans of 73 , $728,891,986$, and $1084 \mathrm{~s}$. Measured strain values are comparable and similar to those shown in [13] research.

The summary of the measurements gathered by the road truck traffic while using FBG sensors is shown in Figure 10. Here, a focus is made on the road's truck traffic, not the traffic made by the passenger cars, as trucks cause the highest applied strain values and damage to the road pavement. The graph represents the generated truck strain value histogram. It is important to add that the strain value histogram contains all the measurement data, not only those presented in Figure 9.

As it can be seen in the histogram, trucks most often (33\% of the time) can be put into the category that generates strain of $300-350 \mu \mathrm{m} / \mathrm{m}$. If all of the data is collected and compared, then trucks, on average, generate $282 \mu \mathrm{m} / \mathrm{m}$ strain value each.

\section{Conclusions}

In this paper, a framework for implementation of FBG optical sensors for structural health monitoring of road pavement was demonstrated. The framework consists of the sensor integration into the A2 road Riga-Sigulda-Estonia, and validation of sensor strain and temperature readings through the use of the falling weight deflectometer (FWD) equipment, which, according to the European practice, is typical for load testing of roads. FWD equipment with the calibrated load was used to help testing the sensor's integration method and evaluating the accuracy of the measurements.

A parametric study was conducted where the measured strain readings from the embedded FBG sensors were compared in summer and autumn sessions when the temperature difference of the road pavement was about $13^{\circ} \mathrm{C}$ (as measured with the embedded FBGs) and at different locations of falling load plate of the FWD with respect to the location of the FBG sensor. It was found that, first of all, the strain values were higher in warmer weather. This can be explained because of the stiffness that decreases at higher temperatures so as a result, strain values are increasing.

As it can be seen in the results with FBG sensors, it is possible to precisely detect (the relative scatter 4.8-12.8\%) strain values, which allows the evaluation of the real operation of the pavement structure under load circumstances.

Finally, a monitoring of the real-time truck traffic on a temporary road with a high annual average daily car traffic and annual average daily truck traffic was conducted. From the monitoring results, the typical strain values generated by the passing trucks were determined to be, on average, $282 \mu \mathrm{m} / \mathrm{m}$, but the most probable value (33\%) is within the range of $300-350 \mu \mathrm{m} / \mathrm{m}(325 \mu \mathrm{m} / \mathrm{m}$ averagely). When the road pavement is underdesigned, the applied strain is suffciently higher, which might cause fatigue failures under repeated loads.

When using FBG sensors solutions, it can be determined at what time the relative deformation limits for a particular road pavements concrete material are exceeded that allows validating and verifying the designed road construction solutions.

Although it has been shown that the installation of FBG sensors into road pavements provides effective means of monitoring the structural integrity of roads under traffic, there are challenges. Firstly, providing the necessary protection of the bare optical fibers in a form of durable packaging, secondly, to account for the varying seasonal temperatures when analyzing the measured strain values.

Based on the obtained results, authors are continuing the research, where the FBG sensors are integrated in the road pavement during the asphalt laying process. Further investigating of the FWD and FOS combination approach would help to understand the structural behavior of the pavement structure, including back-calculations and forward calculations in the pavement design.

Therefore, by using FBG sensors, which can be integrated into the road construction process or after that, the fatigue of such road structures can be monitored over time. This approach could be used for the prediction of different road pavement structure life cycles, so enabling efficient use, maintenance, and timely repairs of the public roads lead to the overall safety of the transportation system. 


\section{Data Availability}

The data used to support the findings of this study are available from the first author upon request.

\section{Conflicts of Interest}

The authors declare that there is no conflict of interest regarding the publication of this paper.

\section{Acknowledgments}

We would like to thank enterprise Binders Ltd. for granting access to the A2 road section and SJSC Latvian State Roads for proving the Dynatest 8000 FWD equipment. This work has been supported by the European Regional Development Fund Project No. 1.1.1.1/16/A/072.

\section{References}

[1] A. Abdelgawad and K. Yelamarthi, "Internet of Things (IoT) platform for structure health monitoring," Wireless Communications and Mobile Computing, vol. 2017, Article ID 6560797, 10 pages, 2017.

[2] H. Wang, W. Liu, J. He et al., "Functionality enhancement of industrialized optical fiber sensors and system developed for full-scale pavement monitoring," Sensors, vol. 14, no. 5, pp. 8829-8850, 2014.

[3] J. Xie, H. Li, L. Gao, and M. Liu, "Laboratory investigation of rutting performance for multilayer pavement with fiber Bragg gratings," Construction and Building Materials, vol. 154, pp. 331-339, 2017.

[4] W. Zhaoxia, Y. Dongmei, and L. Zhiquan, "Bridge structure monitoring system based on practical FBG," in 2008 IEEE International Conference on Automation and Logistics, pp. 14, Qingdao, China, September 2008.

[5] Q. Jin, Z. Liu, J. Bin, and W. Ren, "Predictive analytics of inservice bridge structural performance from SHM data mining perspective: a case study," Shock and Vibration, vol. 2019, Article ID 6847053, 11 pages, 2019.

[6] H. Xu, F. Li, W. Zhao, S. Wang, Y. Du, and C. Bian, "A high precision fiber Bragg grating inclination sensor for slope monitoring," Journal of Sensors, vol. 2019, Article ID 1354029, 7 pages, 2019.

[7] T. Yiqiu, W. Haipeng, M. Shaojun, and X. Huining, "Quality control of asphalt pavement compaction using fibre Bragg grating sensing technology," Construction and Building Materials, vol. 54, pp. 53-59, 2014.

[8] G. Rajan, Ed., Optical Fiber Sensors: Advanced Techniques and Applications, University of New South Wales, School of Electrical Engineering and Telecommunications, UNSW Australia, CRC Press Taylor \& Francis Group, 2015.

[9] M. D. Fatima, F. Domingues, and A. Radwan, Optical Fiber Sensors for IoT and Smart Devices, Springer Briefs in Electrical and Computer Engineering, I3N \& Physics Department, University of Aveiro, Portugal, 2017.

[10] Y. C. Manie, R. K. Shiu, P. C. Peng et al., "Intensity and wavelength division multiplexing FBG sensor system using a Raman amplifier and extreme learning machine," Journal of Sensors, vol. 2018, Article ID 7323149, 11 pages, 2018.
[11] K. O. Hill, Y. Fujii, D. C. Johnson, and B. S. Kawasaki, "Photosensitivity in optical fiber waveguides: application to reflection filter fabrication," Applied Physics Letters, vol. 32, no. 10, pp. 647-649, 1978.

[12] R. Montagne, "FTTH Forecast for Europe, Europe broadband status, market forecast by 2020 and 2025," in FTTH Council Europe Conference, Netherlands, Amsterdam, March 2019.

[13] P. Kara De Maeijer, W. Van den Bergh, and C. Vuye, "Fiber Bragg grating sensors in three asphalt pavement layers," Infrastructures, vol. 3, no. 2, p. 16, 2018.

[14] P. Kolisoja, N. Vuorimies, A. Kurki, and T. Saarenketo, "Open structural monitoring data from two extensively instrumented road sections - case Aurora," in Proceedings of the XVII European Conference on Soil Mechanics and Geotechnical Engineering: Geotechnical Engineering, foundation of the future. The Icelandic Geotechnical Society, IGS, pp. 1-8, Reykjavik, Iceland, 2019.

[15] P. Skels, R. Janeliukstis, and V. Haritonovs, "Review on structural health interrogation using fiber bragg grating sensors," Engineering for Rural Development, vol. 17, pp. 1346-1353, 2018.

[16] K. Li and J. G. Xie, "Experiment and research of using fiber Bragg grating to monitor the dynamic response of asphalt concrete," Applied Mechanics and Materials, vol. 97-98, pp. 301304, 2011.

[17] Z. Zhou, W. Liu, Y. Huang et al., "Optical fiber Bragg grating sensor assembly for 3D strain monitoring and its case study in highway pavement," Mechanical Systems and Signal Processing, vol. 28, pp. 36-49, 2012.

[18] L. Meng, L. Wang, Y. Hou, and G. Yan, “A research on low modulus distributed fiber optical sensor for pavement material strain monitoring," Sensors, vol. 17, no. 10, p. 2386, 2017.

[19] G. Nosenzo, B. E. Whelan, M. Brunton, D. Kay, and H. Buys, "Continuous monitoring of mining induced strain in a road pavement using fiber Bragg grating sensors," Photonic Sensors, vol. 3, no. 2, pp. 144-158, 2013.

[20] Y. Lei, X. Hu, H. Wang, Z. You, Y. Zhou, and X. Yang, "Effects of vehicle speeds on the hydrodynamic pressure of pavement surface: measurement with a designed device," Measurement, vol. 98, pp. 1-9, 2017.

[21] J.-N. Wang, J.-L. Tang, and H.-P. Chang, "Fiber Bragg grating sensors for use in pavement structural strain-temperature monitoring," in Smart Structures and Materials 2006: Sensors and Smart Structures Technologies for Civil, Mechanical, and Aerospace Systems, vol. 6174, San Diego, United States, March 2006.

[22] Z. Zhou and J. Ou, "Techniques of temperature compensation for FBG strain sensors used in long-term structural monitoring," in Fundamental Problems of Optoelectronics and Microelectronics II, Khabrovsk, Russian Federation, June 2005.

[23] COST 323, European WIM Test Program 1996-1998 (CET \& CMT), Technical report of the Management Committee, draft 2, COST323/WAVE, EC/DGVII, COST Transport, 1996.

[24] P. Ullidtz, Modelling Flexible Pavement Response and Performance, Polyteknisk Forlag, Denmark, 1998.

[25] L. Korkiala-Tanttu, Calculation Method for Permanent Deformation of Unbound Pavement Materials, VTT Technical Research Centre of Finland, Espoo, Finland, 2008.

[26] T. Saevarsdottir and S. Erlingsson, "Deformation modelling of instrumented flexible pavement structure," Procedia Engineering, vol. 143, pp. 937-944, 2016. 
[27] M. Y. Shahin, Pavement Management for Airports, Roads, and Parking Lots, Springer, 2 edition, 2017.

[28] P. Kara De Maeijer, W. Van den Bergh, S. Vanlanduit et al., "Inverse modelling approach-fiber Bragg grating (FBG) measurements in comparison to falling weight deflectometer (FWD) measurements: a review," in 7th International Conference Bituminous Mixtures and Pavements, p. 11, Thessaloniki, Greece, 2019.

[29] P. Kara de Maeijer, G. Luyckx, C. Vuye et al., "Fiber optics sensors in asphalt pavement: state-of-the-art review," Infrastructures, vol. 4, no. 2, p. 36, 2019.

[30] "SJSC Latvian State Roads, online traffic intensity at highway A2 76th km," January 2020, https://lvceli.lv/traffic/. 